\title{
INTEGRATED RISK ASSESSMENT ON ARGON PURIFICATION UNIT BASED ON FMECA AND FUZZY-AHP
}

\author{
Rengga Sanditya $^{1} \mid$ Anda Iviana Junani*2 | Haidar Natsir Amrullah ${ }^{1} \mid$ Wiediartini ${ }^{1}$
}

${ }^{1}$ Safety Engineering Department, Politeknik Perkapalan Negeri Surabaya, Surabaya, Indonesia

${ }^{2}$ Design and Manufacture Engineering Department, Politeknik Perkapalan Negeri Surabaya, Surabaya, Indonesia

\section{Correspondence}

*Anda Iviana Junani, Design and Manufacture Engineering Department, Politeknik Perkapalan Negeri Surabaya, Surabaya, Indonesia. Email:

andaiviana@ppns.ac.id

\section{Present Address}

Gedung Politeknik Perkapalan Negeri Surabaya, Jl. Teknik Kimia, Surabaya 60111, Indonesia

\begin{abstract}
Argon Purification Unit is a processing unit to purify the crude argon using hydrogen gas through an automatic machinery process. Based on the hazardous material and its automatic machinery process, the argon purification unit needs to be assessed for risk control consideration and business performance. This research proposed risk assessment of argon purification unit based on the failure modes using Failure Modes, Effects and Criticality Analysis (FMECA) with Fuzzy Analytical Hierarchy Process (Fuzzy-AHP) approach to minimize the risks and losses. In this research, FMECA is used to identify the potential failure modes, failure mechanism (causes), potential failure effects for each unit component and evaluate the risk by determining risk priority number (RPN). The RPN is the product of severity, occurrence, and detection variables. Then, Fuzzy-AHP is used to determine the weight of each variable based on its hierarchy. The fuzzy-AHP approach aims to increase validity and decrease expert judgment subjectivity in the risk assessment process for each failure mode by considering variables' weight. The result of RPN is gained by multiplying each failure mode's variables by considering the importance of variables. This research results weight of severity is 0.43 , which is the highest of all variables. The highest RPN is 8.76 , shown by the leaked joint of the argon compressor. This research indicates that the application of the fuzzy-AHP approach in FMECA can identify and evaluate the potential risk of the Argon Purification Unit validly and objectively, which provides the different weight of RPN variables.
\end{abstract}

\section{KEYWORDS:}

Argon Purification Unit, FMECA, Fuzzy-AHP, Risk Assessment, Risk Priority Number 


\section{1 | INTRODUCTION}

This research was conducted in Industrial Gas Company, specifically in Argon Purification Unit, an automatic machinery process unit used to purify the crude argon using hydrogen gas. Based on its hazardous material and process, this unit has involved the risk considering what happened in 2013. A fire burns suddenly while the unit was processing automatically. Besides, there was the absence of risk assessment carried out for this unit. This condition had the probability of establishing major accidents, which created direct financial costs indirect economic impacts, like a longer business interruption and its reputation. Also, it caused more substantial concern due to the company's possible overall financial scope ${ }^{\mathbb{1 1}}$. Thus, it is necessary to evaluate the risk of this unit by using Failure Modes Effect and Criticality Analysis (FMECA), a development of FMEA that is used for designing, identifying, and eliminating known and potential failures, problems, errors, and so on from system, before they reach the customer ${ }^{[2]}$.

The FMECA, initially developed by NASA to improve and verify the reliability of space program hardware ${ }^{[3]}$, provides a framework for causes and effects analysis of potential product failures ${ }^{[4]}$. The FMECA is designed to provide information for risk management decision-making ${ }^{[5]}$ by determining the Risk Priority Number (RPN), which is defined as the probability of Occurrence, Severity, and Detectability [6] whose variables are gained by evaluating the ratings from 1 to 10 .

The crisp values of RPNs have been considerably criticized by ${ }^{[5] 7-14]}$ for many reasons. Some are the relative importance of the severity, occurrence, and detectability is not considered as they are acknowledged equally important; different combinations of severity, occurrence, and detectability may result in the same value of RPN, although their hidden risk impacts may be different; it is full of difficulty for severity, occurrence, and detectability to be precisely evaluated however linguistic terms can be adopted to convey much information in FMEA; the use of the multiplication method in the calculation of RPN is questionable and strongly sensitive to variations in criticality factor evaluations.

Thus, Chanamool and Naenna ${ }^{[15]}$ has combined the FMEA and Fuzzy approach to developing the form of prioritization and assessment of the failures suitably for the emergency department's working process by analysis and identification of the failures according to the methodology of FMEA. Fuzzy was used to solve the problem of prioritization and assessment. In a typical Fuzzy if-then rule, the failure modes characterized could not be ranked. There is no way to integrate the relative importance of three risk factors into the fuzzy interpretation system ${ }^{0}$.

Furthermore, You-Peng et al. ${ }^{16}$ proposed a new risk assessment method by combining the FMECA and Fuzzy Analytical Hierarchy Process (FAHP) to make a comprehensive evaluation method for FAHP to assess the risk of three risk factors and each failure mode based on its hierarchy. It is appropriate to rank the prioritized problem by the RPNs of failure mode only for one component. However, it is inappropriate to rank the RPNs of some failure modes in a system. In this study, fuzzy-AHP is used to determine the weight of three risk factors in which expert judgments gain the variables of each failure mode in FMECA according to three risk factors rating from 1 to 10 . Therefore, applying this combination method is appropriate to rank the prioritized problem of all failure modes in a system.

\section{2 | MATERIAL AND METHOD}

This research presents a combination method of FMECA and fuzzy-AHP to determine the risk priority numbers (RPN) of each unit's failure mode. The FMECA and fuzzy-AHP can be done effectively and accurately by establishing a team whose members have a thorough understanding of the systems operations and the mission's requirements. The production supervisor and maintenance staff who have been appropriate with the criterion are selected to be the experts.

\section{1 | FMECA}

FMECA can be divided into two procedures, Failure Mode and Effects Analysis (FMEA) and Criticality Analysis (CA). The FMEA was used for designing, identifying, and eliminating known and potential failures, problems, errors, and so on from system, before they reach the customer [2], which is a handy and effective tool that is capable of determining the root cause by risk, of choosing the ways to detect the potential failures, and to find the ways to prevent or mitigate the consequences of failure, to manage the source of risk ${ }^{[15]}$. In CA, based on what FMEA provides, each failure mode of components in the unit is evaluated and prioritized by determining through the Risk Priority Number (RPN), which is defined as the probability of the 
Severity, Occurrence, and Detectability. These three variables are evaluated using a rating from 1 to 10, as described from Table 1 to Table $3{ }^{3}$. The highest RPN of failure mode is assumed to be the most important and should be given the most priority, but the other is not ignored.

The objective of FMECA is to estimate the failure modes of components and their major effects. The FMECA is usually followed by the other hazard identification techniques proposed by ${ }^{[17]}$. A combination of FMECA and HAZOP provides a more consistent identification of the potential sources of failure and human error.

The FMECA will highlight single-point failures requiring corrective action; aid in developing test method and troubleshooting techniques; provide a foundation for qualitative reliability, maintainability, safety, and logistics analyses; provide estimates of system-critical failure rates; provide a quantitative ranking of the system and subsystem failure modes relative to mission importance, and identify parts and systems most likely to fail. Therefore, by developing FMECA during a facility's design phase, the overall cost will be minimized by identifying a single point and other areas of concern before construction or manufacturing ${ }^{3]}$.

\section{2 | Fuzzy-AHP}

AHP, firstly proposed by Saaty ${ }^{[18]}$ is one of the well-known multi-criteria decision-making techniques. Durmuşoğlu ${ }^{[19]}$ used AHP to determine factors that should be used in evaluating techno-entrepreneurship projects. AHP method was also proposed by [20] to estimate and rank the appropriate renewable energy development barriers. AHP has been one of the most popular and influential methods for group decision-making in project selection for evaluating complex multiple criteria alternatives involving subjective judgment ${ }^{[21]}$. Although the AHP includes experts' opinions and makes a multiple criteria evaluation, AHP is not capable of reflecting human's vague thoughts ${ }^{[22]}$. It is difficult to provide exact numerical values for the criteria and make evaluations that convey the feeling and recognition of objects for decision-makers because of the certainty of information and the vagueness of human feeling and recognition. It makes judgments from experts prefer intermediate than particular emotion the distinction theory improves the comparison process to be more flexible and capable to explain experts' preferences ${ }^{\sqrt{23}}$.

Fuzzy-AHP was firstly developed by Laarhoven and Pedrycz ${ }^{[24]}$. Furthermore, explaining the approach for handling fuzzy-AHP using fuzzy triangular numbers for pairwise comparison scale of fuzzy-AHP and the extent analysis method for the synthetic extent values of the pairwise comparisons was introduced by ${ }^{[25]}$. [26] proposed fuzzy-AHP to find the importance degree of each criterion as the measurable indices of the regenerative technologies. Fuzzy-AHP was combined with the fuzzy reasoning approach by ${ }^{[27]}$ to estimate a hazardous event's risk level in terms of failure frequency, consequence severity, and consequence probability for railway risk management

\section{3 | FMECA Adoption}

FMECA is firstly applied to identify the components' functions of the unit, the potential failure modes, the failure mechanisms (causes), and the effects of each potential failure modes based on the characteristics of Argon Purification Unit functions, its accidents record, and the knowledge and expertise of the experts. Then, the Severity, Occurrence, and Detectability are evaluated by the experts using the rating from 1 to 10 , as described from Table 1 to Table 3

\section{4 | Fuzzy-AHP}

The severity, occurrence, and detectability of each failure mode have been evaluated from the above. Those variables that produce RPN in FMECA need to be evaluated with fuzzy-AHP to determine the weight of each variable. Fuzzy-AHP can be done systematically step by step as the following.

First step is establish the hierarchy of three variables. Based on the FMECA, the evaluation is divided into two levels. The first level is RPN, which is the goal of hierarchy. The second level is three variables that produce RPN: severity, occurrence, and detectability. The evaluation is described in Fig 1

Second step is Fuzzification. In a typical Fuzzy-AHP, pairwise comparisons are needed to evaluate each criterion's importance using the linguistic variables in Table 4 Two experts are found to evaluate the three variables through pairwise comparison. Then, the pairwise is necessary to be checked by determining the Consistency Ratio (CR). The pairwise comparison with CR $<0.1$ means consistent. 
TABLE 1 Severity rankings.

\begin{tabular}{|c|c|c|}
\hline Ranking & Effect & Comment \\
\hline 1 & None & $\begin{array}{l}\text { No reason to expect failure to have any impact on Safety, Health, } \\
\text { Environment, or Mission. }\end{array}$ \\
\hline 2 & Very Low & $\begin{array}{l}\text { Minor disruption to facility function. Repair to failure can be } \\
\text { accomplished during a trouble call. }\end{array}$ \\
\hline 3 & Low & $\begin{array}{l}\text { Minor disruption to facility function. Repair to failure may be longer } \\
\text { than trouble call but does not delay Mission. }\end{array}$ \\
\hline 4 & Low to Moderate & $\begin{array}{l}\text { Moderate disruption to facility function. Some portions of the Mission } \\
\text { may need to be reworked or delayed process. }\end{array}$ \\
\hline 5 & Moderate & $\begin{array}{l}\text { Moderate disruption to facility function. } 100 \% \text { of the Mission may } \\
\text { need to be reworked or process delayed. }\end{array}$ \\
\hline 6 & Moderate to High & $\begin{array}{l}\text { Moderate disruption to facility function. Some portion of Mission is } \\
\text { lost. Moderate delay in restoring function. }\end{array}$ \\
\hline 7 & High & $\begin{array}{l}\text { High disruption to facility function. Some portion of Mission is lost. A } \\
\text { Significant delay in restoring function. }\end{array}$ \\
\hline 8 & Very High & $\begin{array}{l}\text { High disruption to facility function. All of the Mission is lost. A } \\
\text { Significant delay in restoring function. }\end{array}$ \\
\hline 9 & Hazard & $\begin{array}{l}\text { Potential Safety, Health, or Environmental issue. Failure will occur } \\
\text { with a warning. }\end{array}$ \\
\hline 10 & Hazard & $\begin{array}{l}\text { Potential Safety, Health, or Environmental issue. Failure will occur } \\
\text { without warning. }\end{array}$ \\
\hline
\end{tabular}

TABLE 2 Occurence rankings.

\begin{tabular}{|c|c|c|}
\hline Ranking & Failure Rate & Comment \\
\hline 1 & $1 / 10000$ & $\begin{array}{l}\text { Remote probability of occurrence; unreasonable to expect failure to } \\
\text { occur. }\end{array}$ \\
\hline 2 & $1 / 5000$ & $\begin{array}{l}\text { Shallow failure rate. Similar to a past design that has, had low failure } \\
\text { rates for given volume/loads. }\end{array}$ \\
\hline 3 & $1 / 2000$ & Low failure rate based on a similar design for given volume/loads. \\
\hline 4 & $1 / 1000$ & $\begin{array}{l}\text { Occasional failure rate. Similar to a past design that has had identical } \\
\text { failure rates for given volume/loads. }\end{array}$ \\
\hline 5 & $1 / 500$ & $\begin{array}{l}\text { Moderate failure rate. Similar to past designs having moderate failure } \\
\text { rates for given volume/loads. }\end{array}$ \\
\hline 6 & $1 / 200$ & $\begin{array}{l}\text { Moderate to high failure rate. Similar to past designs having moderate } \\
\text { failure rates for given volume/loads. }\end{array}$ \\
\hline 7 & $1 / 100$ & $\begin{array}{l}\text { High failure rate. Similar to past designs having frequent failures that } \\
\text { caused problems. }\end{array}$ \\
\hline 8 & $1 / 50$ & $\begin{array}{l}\text { High failure rate. Similar to past designshaving frequent failures that } \\
\text { caused problems. }\end{array}$ \\
\hline 9 & $1 / 20$ & Very high failure rate. Almost certain to cause problems. \\
\hline 10 & $1 / 10+$ & Very high failure rate. Almost certain to cause problems. \\
\hline
\end{tabular}

Third step is calculating the value of the fuzzy synthetic extent ( $\mathrm{Si}$ ). After the consistent pairwise comparison is made, the fuzzy synthetic extent's value needs to be calculated. The triangular fuzzy number (TFN) from linguistic variables can be denoted by $(1, \mathrm{~m}, \mathrm{u})$ as seen in Fig 2

Mention two triangular fuzzy numbers $\boldsymbol{M}_{1}$ and $\boldsymbol{M}_{2}, \boldsymbol{M}_{1}=\left(l_{1}, m_{1}, u_{1}\right)$ and $\boldsymbol{M}_{2}=\left(l_{2}, m_{2}, u_{2}\right)$. Their operational law is as follows $[25]$ :

$$
\left(l l_{1}, m_{1}, u_{1}\right) \odot\left(l_{2}, m_{2}, u_{2}\right) \approx\left(l_{1} l_{2}, m_{1} m_{2}, u_{1} u_{2}\right)
$$

Let $M_{g} i^{j}$ be values of extent analysis of $i^{\text {th }}$ object for $\mathrm{j}$ goals. Then the value of fuzzy synthetic extent with respect to the $i^{\text {th }}$ object is defined as [1].

$$
S i=\sum_{j=1}^{m} M_{g} i^{j} \odot \llbracket \sum_{i=1}^{n} \sum_{j=1}^{m} M_{g} i^{j} \rrbracket^{-1}
$$


TABLE 3 Testability rankings.

\begin{tabular}{lll}
\hline Ranking & Detectability & Comment \\
\hline 1 & Almost Certain & $\begin{array}{l}\text { Current control(s) almost certain to detect failure mode. Reliable } \\
\text { controls are known with similar processes. }\end{array}$ \\
2 & Very High & $\begin{array}{l}\text { A Very high likelihood of current control(s) will detect failure mode. } \\
\text { High likelihood current control(s) will detect failure mode. }\end{array}$ \\
3 & High & $\begin{array}{l}\text { Moderately high likelihood of current control(s) will detect failure } \\
\text { mode. }\end{array}$ \\
5 & Moderately High & Moderate likelihood of current control(s) will detect failure mode. \\
5 & Moderate & Low likelihood current control(s) will detect failure mode. \\
6 & Low & Very low likelihood current control(s) will detect failure mode. \\
7 & Very Low & Remote likelihood current control(s) will detect failure mode. \\
8 & Remote & Very remote likelihood current control(s) will detect failure mode. \\
9 & Very Remote & No known control(s) available to detect failure mode. \\
10 & Almost & \\
& Impossible &
\end{tabular}

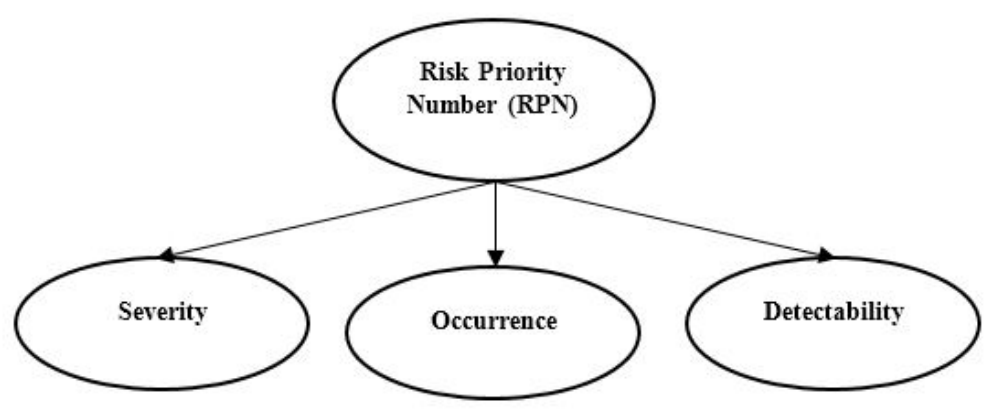

FIGURE 1 The evaluation hierarchy.

TABLE 4 Linguistic terms and their fuzzy scores.

\begin{tabular}{llll} 
Linguistic terms & Fuzzy Score & Linguistic terms & Fuzzy Score \\
\hline Absolute Strong & $(2,5 / 2,3)$ & Very strong & $(3 / 2,2,5 / 2)$ \\
Fairly strong & $(1,3 / 2,2)$ & Slightly strong & $(1,1,3 / 2)$ \\
Equal & $(1,1,1)$ & Slightly weak & $(2 / 3,1,1)$ \\
Fairly weak & $(1 / 2,2 / 3,1)$ & Very weak & $(2 / 5,1 / 2,2 / 3)$ \\
Absolutely weak & $(1 / 3,2 / 5,1 / 2)$ & & \\
\hline
\end{tabular}

Fourth step is determining the degree possible for a convex fuzzy number. After calculating the value of the fuzzy synthetic number, the next step is to determine the degree possibility of the convex fuzzy number using the three probability of convex fuzzy number as follows:

$$
\begin{gathered}
V\left(M_{1} \geq M_{2}\right)=1 \text { if } m_{1} \geq m_{2} \\
V\left(M_{1} \geq M_{2}\right)=0 \text { if } l_{2} \geq l_{1} \\
V\left(M_{2} \geq M_{1}\right)=\left(l_{1}-u_{2}\right) /\left(\left(m_{2}-u_{2}\right)-\left(m_{1}-l_{1}\right)\right)
\end{gathered}
$$

The degree possibility of convex fuzzy number can be defined by

$$
V\left(M \geq M_{1}, M_{2}, \ldots, M_{k}\right)=V\left[\left(M \geq M_{1}\right) \text { and }\left(M \geq M_{2}\right) \text { and } \ldots \text { and }\left(M \geq M_{k}\right)\right]=\min V\left(M \geq M_{i}\right), i=1,2, \ldots, k
$$




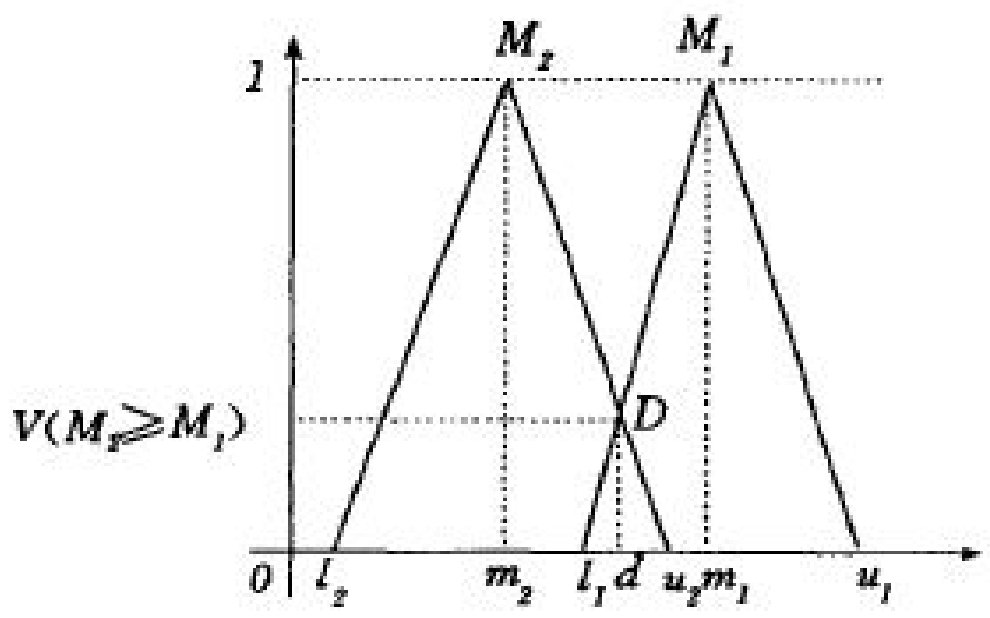

FIGURE 2 The intersection between $M_{1}$ and $M_{2}$.

The last step is Defuzzification. After determining the probability of convex fuzzy number, assume that

$$
d^{\prime}(A i)=\min V\left(S_{i} \geq S_{k}\right)
$$

for $k=1,2, \ldots, n ; k \neq i$. Then the weight vector is given by

$$
W^{\prime}=\left(d^{\prime}\left(A_{i}\right), d^{\prime}\left(A_{2}\right), \ldots, d^{\prime}\left(A_{n}\right)\right)^{T}
$$

Where $A_{i}(i=1,2, \ldots, n)$ are $\mathrm{n}$ elements. The value of the weight vector above is in a fuzzy number. To convert into a nonfuzzy number, normalization is needed. Normalization is applied by dividing each minimum convex fuzzy number of weight vector with the total of the weight vector.

$$
W=\llbracket\left(d\left(A_{1}\right), d\left(A_{2}\right), \ldots, d\left(A_{n}\right)\right) \rrbracket^{T}
$$

Where $W$ is a nonfuzzy number.

\section{3 | RESULTS AND DISCUSSION}

As the following step of doing FMECA and fuzzy-AHP above is done, the research results 27 components of the Argon Purification Unit identified using FMECA. From 27 components resulted in 60 failure modes for the overall components of the unit. The experts evaluated the severity, occurrence, and detectability using a scale from 1 to 10 , as described in Table 1 to Table 3 After the expert evaluated the RPN of failure modes in FMECA, the highest ten RPNs are gained by merely multiplying the severity, occurrence, and detectability, as shown in Table 5

The RPNs in Table 5 is obtained by simply multiplying the three variables. The next step is determining the weight of each variable using Fuzzy-AHP as the following steps:

Fuzzified pairwise comparison for the importance of three variables done by experts is shown in Table 6

Fuzzy synthetic extent for three variables above are given by Eq2 
TABLE 5 The ten highest RPN of typical FMECA.

\begin{tabular}{|c|c|c|c|c|c|}
\hline Item/Functional ID & $\begin{array}{l}\text { Potential } \\
\text { Failure Modes }\end{array}$ & Severity & Occurrence & Detectability & RPN \\
\hline $\begin{array}{l}\text { Argon compressor/Compress the crude argon } \\
\text { mixed the water with pressure. }\end{array}$ & Lacked joint & 9 & 9 & 8 & 648 \\
\hline $\begin{array}{l}\text { Flange 03/As a connection between hydrogen } \\
\text { gas input and U500 unit. }\end{array}$ & $\begin{array}{l}\text { Lacked } \\
\text { connection }\end{array}$ & 10 & 7 & 8 & 560 \\
\hline $\begin{array}{l}\text { Deoxidation Vessel/React the oxygen in crude } \\
\text { argon using hydrogen gas by heating using } \\
\text { Palladium catalyst. }\end{array}$ & Gagged & 7 & 5 & 8 & 280 \\
\hline $\begin{array}{l}\text { Analyzer/Analyze the content of oxygen gas in } \\
\text { the crude argon and transfer the signal to the } \\
\text { Analyzer Indicator. }\end{array}$ & $\begin{array}{l}\text { Inaccurate } \\
\text { analysis }\end{array}$ & 6 & 5 & 9 & 270 \\
\hline $\begin{array}{l}\text { Pressure Indicator/Indicate the pressure of the } \\
\text { crude argon flow. }\end{array}$ & $\begin{array}{l}\text { Inaccurate } \\
\text { indication }\end{array}$ & 7 & 5 & 7 & 245 \\
\hline $\begin{array}{l}\text { Flange 03/As a connection between hydrogen } \\
\text { gas input and U500 unit. }\end{array}$ & $\begin{array}{l}\text { A Crack of } \\
\text { welded joint }\end{array}$ & 8 & 4 & 7 & 224 \\
\hline $\begin{array}{l}\text { Argon compressor/Compress the crude argon } \\
\text { mixed the water with pressure. }\end{array}$ & Noise & 9 & 6 & 4 & 216 \\
\hline $\begin{array}{l}\text { Gate Valve/Open and close the flow of crude } \\
\text { argon gas. }\end{array}$ & $\begin{array}{l}\text { Delayed } \\
\text { opening }\end{array}$ & 4 & 9 & 6 & 216 \\
\hline $\begin{array}{l}\text { Pressure Shutdown High/Shutdown the argon. } \\
\text { Compressor when the pressure was increasing } \\
\text { suddenly. }\end{array}$ & $\begin{array}{l}\text { Fail to detect } \\
\text { the pressure } \\
\text { increasing }\end{array}$ & 9 & 4 & 6 & 216 \\
\hline $\begin{array}{l}\text { Preheater/Heat the crude argon and hydrogen gas } \\
\text { until they reach } 350^{\circ} \mathrm{C} \text {. }\end{array}$ & Overheating & 10 & 5 & 4 & 200 \\
\hline
\end{tabular}

TABLE 6 Fuzzified pairwise comparison.

\begin{tabular}{llll}
\hline & Severity & Occurrence & Detectability \\
\hline Severity (1) & $(1,1,1)$ & $(1,1,3 / 2)$ & $(1,3 / 2,2)$ \\
Occurrence $(2)$ & $(2 / 3,1,1)$ & $(1,1,1)$ & $(1,1,3 / 2)$ \\
Detectability (3) & $(1 / 2,2 / 3,1)$ & $(2 / 3,1,1)$ & $(1,1,1)$ \\
\hline CR $=0$. & & &
\end{tabular}

$S_{1}=(3,3.5,4.5) \times\left(\frac{1}{11}, \frac{1}{9.17}, \frac{1}{7.84}\right)=(0.27,0.38,0.57)$

$S_{2}=(2.67,3,3.5) \times\left(\frac{1}{11}, \frac{1}{9.17}, \frac{1}{7.84}\right)=(0.24,0.33,0.45)$

$S_{3}=(2.17,2.67,3) \times\left(\frac{1}{11}, \frac{1}{9.17}, \frac{1}{7.84}\right)=(0.20 .0 .29,0.38)$

The degree possibility of convex fuzzy numbers is gained by:

$V\left(S_{1} \geq S_{2}\right)=1$,

using the Eq 3 probability based on $m_{1} \geq m_{2}$

$V\left(S_{1} \geq S_{3}\right)=1$

$V\left(S_{2} \geq S_{1}\right)=\frac{l_{1}-u_{2}}{\left(\left(m_{2}-u_{2}\right)-\left(m_{1}-l_{1}\right)\right)}=\frac{0.27-0.45}{((0.33-0.45)-(0.38-0.27))}=0.78$

using the Eq 5 probability based on their $m$ and $l$ values.

$$
\begin{aligned}
& V\left(S_{2} \geq S_{3}\right)=1 \\
& V\left(S_{3} \geq S_{1}\right)=\frac{l_{1}-u_{3}}{\left(\left(m_{3}-u_{3}\right)-\left(m_{1}-l_{1}\right)\right)}=\frac{0.27-0.38}{((0.29-0.38)-(0.38-0.27))}=0.55 \\
& V\left(S_{3} \geq S_{2}\right)=\frac{0.24-0.38}{\left(\left(m_{3}-l_{3}\right)-u_{3}\left(m_{2}-l_{2}\right)\right)}=\frac{(0.29-0.38)-(0.33-0.24))}{((0.24)}=0.78 \\
& d^{\prime}(\text { Severity })=V\left(S_{1} \geq S_{2}, S_{3}\right)=\min (1,1)=1.0 \\
& d^{\prime}(\text { Occurrence })=V\left(S_{2} \geq S_{1}, S_{3}\right)=\min (0.78,1)=0.78 \\
& d^{\prime}(\text { Detectability })=V\left(S_{3} \geq S_{1}, S_{1}\right)=\min (0.55,0.78)=0.55
\end{aligned}
$$

After the convex fuzzy numbers are obtained, we take defuzzification to normalize the fuzzy number into a nonfuzzy number. 
TABLE 7 The ten highest RPN obtained by Fuzzy-AHP.

\begin{tabular}{|c|c|c|c|c|c|}
\hline Item/Functional ID & $\begin{array}{l}\text { Potential } \\
\text { Failure Modes }\end{array}$ & $\begin{array}{c}\text { Severity } \\
0.43\end{array}$ & $\begin{array}{c}\text { Occurrence } \\
\mathbf{0 . 3 3}\end{array}$ & $\begin{array}{l}\text { Detectability } \\
\quad 0.24\end{array}$ & RPN \\
\hline $\begin{array}{l}\text { Argon compressor/Compress the crude argon } \\
\text { mixed the water with pressure. }\end{array}$ & Lacked joint & 9 & 9 & 8 & 8,76 \\
\hline $\begin{array}{l}\text { Flange } 03 / \text { As a connection between hydrogen } \\
\text { gas input and U500 unit. }\end{array}$ & $\begin{array}{l}\text { Lacked } \\
\text { connection }\end{array}$ & 10 & 7 & 8 & 8,53 \\
\hline $\begin{array}{l}\text { Preheater/Heat the crude argon and hydrogen gas } \\
\text { until they reach } 350^{\circ} \mathrm{C} \text {. }\end{array}$ & Overheating & 10 & 5 & 4 & 6,91 \\
\hline $\begin{array}{l}\text { Argon compressor/Compress the crude argon } \\
\text { mixed the water with pressure. }\end{array}$ & Noise & 9 & 6 & 4 & 6,81 \\
\hline $\begin{array}{l}\text { Insulation Line/Keep the temperature of the fluid } \\
\text { inside the pipe stable. }\end{array}$ & $\begin{array}{l}\text { Fail to stabilize } \\
\text { the temperature }\end{array}$ & 9 & 2 & 9 & 6,69 \\
\hline $\begin{array}{l}\text { Pressure Shutdown High/Shutdown the argon } \\
\text { compressor when the pressure was increasing } \\
\text { suddenly. }\end{array}$ & $\begin{array}{l}\text { Fail to detect } \\
\text { the pressure } \\
\text { increasing }\end{array}$ & 9 & 4 & 6 & 6,63 \\
\hline $\begin{array}{l}\text { Argon compressor/Compress the crude argon } \\
\text { mixed the water with pressure. }\end{array}$ & $\begin{array}{l}\text { Heated } \\
\text { compressor }\end{array}$ & 10 & 4 & 4 & 6,58 \\
\hline $\begin{array}{l}\text { Deoxidation Vessel/React the oxygen in crude } \\
\text { argon using hydrogen gas by heating using } \\
\text { Palladium catalyst. }\end{array}$ & Gagged & 7 & 5 & 8 & 6,58 \\
\hline $\begin{array}{l}\text { Flow Valve/Open and close the crude argon flow } \\
\text { to U500. }\end{array}$ & Fail to close & 9 & 3 & 7 & 6,54 \\
\hline $\begin{array}{l}\text { Pressure Safety Valve/Exit the crude argon gas } \\
\text { when overpressure happens. }\end{array}$ & $\begin{array}{l}\text { Lacked } \\
\text { pressure safety } \\
\text { valve }\end{array}$ & 9 & 3 & 7 & 6,54 \\
\hline
\end{tabular}

$W^{\prime}=(1,0.78,0.55)^{T}$

$W_{s}$ everity $=\frac{1}{(1+0.78+0.55)}=\frac{1}{2.33}=0.43$

$W_{o}$ ccurrence $=\frac{0.78}{(1+0.78+0.55)}=0.78 / 2.33=0.33$

$W_{d}$ etectability $=\frac{0.55}{(1+0.78+0.55)}=0.55 / 2.33=0.24$

The fuzzy-AHP proposed three variables' weight to determine the importance of which the total is equal to 1 . The three variables' weight is obtained as $(0.43,0.33,0.24)$, which shows that severity is the most important factor that contributes to the risk. After the overall step is done, the new RPN of failure modes is gained, and the five highest RPNs are shown in Table 7

From 60 failure modes, the ten failure modes with the highest RPNs are obtained. Based on the ten highest RPN has shown in Table 5 and Table 7 it is significantly different, especially for the third until the tenth rank of RPN. Because fuzzy-AHP is used to determine the importance of three variables that produces RPN, the experts propose the most important variable that produces RPN is severity, which has a 0.43 value of weight. It is appropriate to what happened in the site: the overheater's overheater is more dangerous than the gagged oxidation vessel, according to the effects of overheating may be overpressure and take an accidental explosion. Like the fourth rank, the argon compressor's noise may be more dangerous than an inaccurate analysis of the analyzer because it impacts employees' hearing who work around the unit.

Based on the evaluation in a site, an erroneous indication of pressure indicator is not more dangerous than the insulation line's failure, which may create an explosion caused by overtemperature. At the sixth rank, the pressure shutdown high fails to detect the increased pressure has more risks than the crack of the welded joint of flange 03 . The seventh rank in Table 5 is the argon compressor's noise, while in Table 7 is the heated argon compressor, the noise of the argon compressor is the fourth rank in the fuzzy-AHP evaluation. The eighth fuzzy-ahp assessment rank is the gagged deoxidation vessel. The ninth and tenth ranks are for each the flow valve failing to close, and the lack of pressure safety valve. The risk evaluation using the fuzzy-AHP approach results in a more accurate RPN according to what happens in the site supported by the experts. It is proved fuzzy-AHP provides accurate results similar to the real condition in the site.

From the fuzzy-AHP evaluation above, the highest ten RPN of failure modes are obtained. The lacked joint of the compressor with RPN 8.76 has the highest RPN among the lacked connection of flange 03 with RPN 8.53; the overheating of preheater with RPN 6.91; the noise of argon compressor with RPN 6.81; the failed temperature stabilization of insulation line with RPN 6.69; the pressure shutdown high fails to detect the pressure increasing with RPN 6.63; the heated argon compressor and the gagged of deoxidation vessel with RPN 6.58, and the flow valve fails to close, and the pressure safety valve lacks with RPN 6.54. After 
gaining the highest RPN of failure mode in the Argon Purification Unit, we can take the most appropriate actions to minimize the risks and losses. So, the accidents may not occur, and the company's business will not be affected by the losses of the failures.

\section{4 | CONCLUSION}

FMECA, a development of FMEA, is designed to provide information for risk control consideration by identifying each component's potential failure modes and evaluating the three risk factors to obtain the risk priority number, which is accepted as they are equally important. It has been criticized for many reasons, such as the importance of three risk factors being ignored, the evaluation is imprecise, the procedures of multiplying the risk factors are questionable, and the evaluation result is not dependent on the site's real condition.

Based on the criticism for gaining the RPN in a typical FMECA, the fuzzy-AHP approach is contributed to improving the weaknesses by determining the weight of three risk factors to provide the importance of each factor. It is also done by the experts who understand the real condition of the unit and the site. The result of using fuzzy-AHP is to find the weight of prioritized risk factors that impacts the RPN. The severity has the highest weight among the occurrence and the detectability. Their weight values are for each $0.43,0.33$, and 0.24 . Both methods are the tools to identify the Argon Purification Unit's risk precisely and effectively for providing specific information for risk control consideration in safety-related to business and management.

For further research, our study's results can be continued to determine the alternatives for risk control using multi-criteria decision-making techniques. Besides, it can be compared with the other multi-criteria decision-making techniques such as fuzzy ANP.

\section{5 | ACKNOWLEDGEMENT}

The authors would like to thank the company's management, which permitted us to take the Argon Purification Unit to be the object of study. We want to thank the experts who would be good at teamwork while finishing this research. This research is supported by lecturers of the Shipbuilding Institute of Polytechnic Surabaya.

\section{References}

1. Gerbec M, Kontić B. Safety related key performance indicators for securing long-term business development - A case study. Safety Science 2017;98:77-88.

2. Stamatis DH. Failure Mode and Effect Analysis - FMEA from Theory to Execution. 2nd ed. Milwaukee: American Society for Quality (ASQ); 2013.

3. Department of the US Army. Failure modes, effects and Criticality Analysis (FMECA) for command, control, computer, intelligence, surveillance and reconnaissance (C4ISR) Facilities; 2006.

4. Chin KS, Chan A, Yang JB. Development of a fuzzy FMEA based product design system. International Journal of Advanced Manufacturing Technology 2008;36(7-8).

5. Pillay A, Wang J. Modified failure mode and effects analysis using approximate reasoning. Reliability Engineering and System Safety 2003;79(1):69-85.

6. George JJ, Renjith VR, George P, George AS. Application of fuzzy failure mode effect and criticality analysis on unloading facility of LNG terminal. Journal of Loss Prevention in the Process Industries 2019;61:104-113.

7. Sartor M, Cescon E. Failure mode and effect analysis (FMEA). In: Quality Management: Tools, Methods and Standards Emerald Group Publishing Ltd.; 2019.p. 117-127.

8. Ciani L, Guidi G, Patrizi G. A Critical Comparison of Alternative Risk Priority Numbers in Failure Modes, Effects, and Criticality Analysis. IEEE Access 2019;7:92398-92409. 
9. Braglia M, Bevilacqua M. Fuzzy modelling and analytical hierarchy processing as a means of quantifying risk levels associated with failure modes in production systems. Technology, Law and Insurance 2000 sep;5(3-4):125-134. https: //www.tandfonline.com/doi/abs/10.1080/135993700750364341.

10. Braglia M, Frosolini M, Montanari R. Fuzzy TOPSIS Approach for Failure Mode, Effects and Criticality Analysis. Quality and Reliability Engineering International 2003;19(5):425-443.

11. Chang CL, Liu PH, Wei CC. Failure mode and effects analysis using grey theory. Integrated Manufacturing Systems 2001;12(3):211-216.

12. Gilchrist W. Modelling failure modes and effects analysis. International Journal of Quality \& Reliability Management 1993 may;10(5):16-23.

13. Sankar NR, Prabhu BS. Modified approach for prioritization of failures in a system failure mode and effects analysis. International Journal of Quality and Reliability Management 2001;18(3):324-336.

14. Wang YM, Chin KS, Poon GKK, Yang JB. Risk evaluation in failure mode and effects analysis using fuzzy weighted geometric mean. Expert Systems with Applications 2009;36(1):1195-1207.

15. Chanamool N, Naenna T. Fuzzy FMEA application to improve decision-making process in an emergency department. Applied Soft Computing Journal 2016;43:441-453.

16. You-Peng Z, Zheng-Jie X, Hong-Sheng S. Risk assessment on railway signal system based on Fuzzy-FMECA method. Sensors and Transducers 2013;156(9):203-210.

17. Giardina M, Morale M. Safety study of an LNG regasification plant using an FMECA and HAZOP integrated methodology. Journal of Loss Prevention in the Process Industries 2015;35:35-45.

18. Yunita D, Ayshwarya B, Ridhawati E, Huda M, Hashim A, Teh KSM, et al. Application of analytical hierarchy process method in laptop selection. International Journal of Recent Technology and Engineering 2019;8(2S3):1603-1607.

19. Durmuşoğlu ZDU. Assessment of techno-entrepreneurship projects by using Analytical Hierarchy Process (AHP). Technology in Society 2018;54:41-46.

20. Ghimire LP, Kim Y. An analysis on barriers to renewable energy development in the context of Nepal using AHP. Renewable Energy 2018;129(A):446-456.

21. Sossa JWZ, Halal W, Zarta RH. Delphi method: analysis of rounds, stakeholder and statistical indicators. Foresight 2019;21(5):525-544.

22. Seçme NY, Bayrakdaroğlu A, Kahraman C. Fuzzy performance evaluation in Turkish Banking Sector using Analytic Hierarchy Process and TOPSIS. Expert Systems with Applications 2009 nov;36(9):11699-11709.

23. Kahraman C, Cebeci U, Ulukan Z. Multi-criteria supplier selection using fuzzy AHP. Logistics Information Management 2003 dec;16(6):382-394.

24. Kwiesielewicz M. A note on the fuzzy extension of Saaty's priority theory. Fuzzy Sets and Systems 1998;95(2):161-172.

25. Aggarwal R, Singh S. AHP and Extent Fuzzy AHP Approach for Prioritization of Performance Measurement Attributes. Engineering and Technology 2013;7(1):6-11.

26. Hsu YL, Lee CH, Kreng VB. The application of Fuzzy Delphi Method and Fuzzy AHP in lubricant regenerative technology selection. Expert Systems with Applications 2010;37(1):419-425.

27. An M, Chen Y, Baker CJ. A fuzzy reasoning and fuzzy-analytical hierarchy process based approach to the process of railway risk information: A railway risk management system. Information Sciences 2011;181(18):3946-3966. 
How to cite this article: Sanditya R., Juniani A.I., Amrullah H.N., Wiediartini (2020), Integrated Risk Assessment on Argon Purification Unit Based on FMECA and Fuzzy-AHP, IPTEK The Journal of Technology and Science, 31(3):249-259. 